\title{
The Three Markets for Private Insurance *
}

\author{
by Karl Borch **
}

\section{Introduction}

1.1. The starting point of this study is the trivial observation that insurance is an economic activity of some importance. Hence it should be possible - and useful - to study problems in insurance with the tools and methods developed for use in general economic analysis. To some extent this is true, but the task is not always easy and straight forward. Insurance often appears as a special or exceptional case among economic activities, and seems to require its own concepts and methods of analysis. This becomes particularly striking when one tries to construct an economic theory of insurance, which can be integrated into the general economic theory.

1.2. It seems very difficult to develop an economic theory of insurance which is so general that it will include all kinds of insurance. It is therefore desirable, at least at the present stage to set the aspiration level lower and study less general theories, and it seems convenient to divide the activities called insurance into the following three classes, and discuss them separately :

(i) Life insurance, with a possible subdivision into annuities, and ordinary life insurance with payment at death.

(ii) Business insurance covering commercial risks of different kinds.

(iii) Household insurance bought by the ordinary consumer as protection against the risks of everyday life.

It would be an exaggeration to claim that each class requires its own separate economic theory, but it will be shown in the following that analysis of these three classes will have to draw on distinctly different parts of economic theory.

1.3. It will also be shown that this three-way classification may be natural in other contexts, and that it is used in practice, at least informally. The three classes of insurance are sold in different markets, and it is reasonable to assume that they usually are sold by different sections of the marketing department of an insurance company. The three groups of buyers may also feel differently about the need for government protection. This is reflected in the legislation of many countries, which

* Conference presented in Brussels on January 12, 1981 at the "Université Libre de Bruxelles", under the auspices of the Royal Association of Belgian Actuaries (Brussels) and the CORE (Center for Operations Research and Econometrics, Louvain-la-Neuve).

** Professor at the Norwegian School of Economics and Business Administration, Bergen. 
treats the three classes separately, both with regard to the formal requirements of the insurance contract and the supervision of private insurance companies.

Hence the classification which helps us to gain insight in a purely theoretical analysis, may be useful also in practice, and have practical implications.

\section{The economic theory of insurance}

2.1. It is natural, and indeed very common to talk about the insurance market. The commodity which is bought and sold in this market is security, and the price should, according to theory, be determined so that supply equals demand. This idea can be traced back at least to Adam Smith, and during the following two centuries several authors made gallant attempts to develop an economic theory of insurance. This early work, i.a. by Willet [1901] and Lindenbaum [1931], is today only of historical interest, and is rather unsatisfactory by contemporary standards. The reason is obviously that it is only during the last 30 years that economic theory has developed the tools required to analyse the uncertainty inherent in insurance. It may however be of some interest to recall that Böhm-Bawerk [1881] wrote his Habilitationsarbeit on the values which one should assign to contingent claims, apparently without realizing that this problem was equivalent to that of setting insurance premiums. In later years, when he became the leader of the Austrian School, he had little to say about uncertainty, and usually made the standard assumptions about complete certainty and complete foresight. Böhm-Bawerk served several times as minister of finance in Austria-Hungary, but he did not hold this office in 1909 when the Sixth International Congress of Actuaries met in Vienna. This congress, which became a landmark in the history of actuarial risk theory, was opened by the minister of finance. It is amusing, though hardly useful, to ponder how insurance theory could have developed if the opening address had been given by Böhm-Bawerk, and if he had realized that actuaries were struggling to give a mathematical formulation to the problems he himself had studied in his youth.

2.2. Insurance has developed and prospered in the absence of any relevant economic theories, and it is legitimate to ask if one really needs an economic theory for this activity. One could of course answer in the spirit of the mountain climber that a theory must be created "because it is not there". A more conventional answer would run along the following lines :

In economic theory one makes assumptions about people's preferences. From these assumptions one then deduces how rational people will make their economic decisions, and how they will, or should organize their society. The implications which one can derive from such models will often be contradicted by the economic behaviour which one can observe in presumably rational people. In such cases the explanation will frequently be that there is something wrong with the assumptions. It may however also be that the people are not quite rational, for instance because there are conventional, institutional, or ethical aspects which prevent them from reaching an optimal situation. In the latter case the theory can be useful by indicating reforms which are required or desirable. 
2.3. The remarks above make rather modest claims for the usefulness of economic theory. More ambitious theoreticians will use the theory to develop hypotheses which can be tested only by refined statistical methods, and which eventually can lead to models which can be used to make reliable forecasts. In the current insurance literature one can find an abundance of studies with such high aspirations, and some of them may be directly useful in practice. It seems however undeniable that some of this work is premature, in the sense that the author may be too impatient and seek to apply an oversimplified theory to solve problems from real life. We live and write insurance in a complex world, and simple theories can be outright dangerous.

\section{The three classes of Insurance}

3.1. Insurance is, as we have observed, an important sector in the modern economy. The sector is also complex, with many facets, and it is difficult even to outline its boundaries. There will always be borderline activities which may or may not be considered as insurance. For instance in some forms of credit insurance the premium is just an addition to the interest on a loan which is considered as risky. Thus the insurance becomes indistinguisable from the traditional banking functions of evaluating the risk of a loan and charge the appropriate rate of interest.

It is difficult to give a satisfactory and general definition of insurance. Authors of textbooks usually try, and often seem to start with a fairly simple definition, adding a long list of qualifications and exceptions before they are satisfied, or give up. More important than definitions in textbooks are those given by law. It is interesting to note that the legislation of many countries leaves the term insurance virtually undefined, so that it is up to the courts to decide if any particular economic transaction shall be considered as insurance, and hence be subject to the laws and regulations governing insurance.

3.2. These observations indicate that it may be difficult not only to develop theories, but even just to make any statement which is valid for insurance in general. To reach useful conclusions, one must subdivide the broad subject, and each of the many parts must be studied and discussed separately. This observation is of course trivial. Insurance has been subdivided in branches in almost every conceivate manner, as one can verify from any textbook, from the organizational chart of most insurance companies, or from the official statistics of various countries. Different classifications are suitable for different purposes, and no particular merits can be claimed for the three-way system presented in the Introduction, except that it seems convenient for more different purposes than many of the more conventional systems of classification.

3.3. The relative importance of the three groups of insurance may seem to differ from one country to another, depending on the definition used in the insurance statistics. The figures in the table below are taken from the official statistics of Sweden, since that country is among the very few which try to break down insurance premiums according to the type of insured. 
Direct insurance premiums received by Swedish companies in 1977. Million Swedish Kronor.

\begin{tabular}{|c|c|c|c|}
\hline & $\begin{array}{c}\text { Life } \\
\text { insurance }\end{array}$ & $\begin{array}{l}\text { Business } \\
\text { insurance }\end{array}$ & $\begin{array}{c}\text { Household } \\
\text { insurance }\end{array}$ \\
\hline Group pension and health insurance & 4475 & & \\
\hline Dther life insurance & 3130 & & \\
\hline
\end{tabular}

General property, pecuniary loss and liability insurance

Motor vehicle insurance

Marine and transportation insurance 675

Livestock insurance

Credit insurance 70

Aviation insurance

In Sweden most of the pension plans established by private firms are insured, and will enter the insurance statistics. In many countries private pension plans are not under the same supervision as insurance companies, and will not be included in the insurance statistics.

Of the premiums for motor vehicles, a substantial part, probably about $30 \%$, is paid for commercial vehicles, and should be considered as business insurance.

With adjustments for those two elements, one is led to conclude that the three classes of insurance are of about equal importance in industrial countries with a well developed social security system.

3.4. The insurance statistics of most countries have their peculiarities, and Sweden has its fair share. There is no need to discuss these in detail, but two points may be worth mentioning :

In Sweden a substantial part of the direct aviation insurance is written by a Scandinavian pool, and will be recorded as reinsurance received from abroad in the official statistics. This means that figures for direct business insurance will be underestimated.

All insurance of farm property is classified as business insurance, although an important part covers residential buildings, which more appropriately should be listed as Household insurance. This means of course that the figures for business insurance are overestimated. 


\section{Life insurance - Theory}

4.1. Life insurance is essentially a form of saving, and to study the basic mechanics of this form of insurance, it is convenient first to study conventional saving. Assume that a person's income can be represented by a continuous function of time $y(t)$. Similarly one can assume that his planned expenditure on consumption can be represented by a function $c(t)$. Whether a particular consumption plan can be carried out will in the first place depend on the facilities for saving and borrowing, i.e. on the possibilities of using income in one period to cover expenditure on consumption in another period.

The simplest assumption about these facilities is that the consumer can save or borrow any amount at the same force of interest $\delta$. For a given income and an arbitrary consumption plan the consumer's net savings (positive or negative) at time $t$ will be

$$
S(t)=e^{s t} \int_{0}^{t} e^{-\delta s}\{y(s)-c(s)\} d s .
$$

4.2. It is natural to assume that there are some limits to the debt which the consumer is allowed to accumulate. A very strict condition would be

$$
S(t) \geqslant 0 \quad \text { for all } t
$$

This condition implies that the consumer is never allowed to be in debt. This may be realistic, although in practice there would be exceptions if the expenditure is used to buy durable consumer's gonds which are acceptable as collateral for a loan.

A weaker condition would be

$$
S(T) \geqslant 0
$$

where $T$ is some planning horizon. This condition implies that the consumer must settle his debts before time $T$.

4.3. A natural planning horizon is the time when the consumer's income ceases, because he retires or dies. The time of death is uncertain, so it is natural to require that either condition hold only as an expectation. Let $\pi(t)=$ the probability that the consumer shall be alive at time $t$. Clearly $\pi(t)$ is a non-increasing function of $t$, so that $\pi(0)=1$ and $\pi(\infty)=0$. In the standard actuarial notation

$$
\pi(t)=\frac{\ell_{x+t}}{\ell_{x}}
$$


where $x$ stands for the person's age. This notation will however not be used in the following, since age will not play any part in the discussion. The probability density of the event that death occurs at time $t$, will then be $-\pi^{\prime}(t)$.

Taking the expectation of (1), one obtains

$$
-\int_{0}^{\infty} \int_{0}^{t} e^{-\delta s}\{y(s)-c(s)\} d s \pi^{\prime}(t) d t=
$$

$$
\int_{0}^{\infty} e^{-\delta s}\{y(s)-c(s)\} \pi(s) d s \geqslant 0
$$

The condition says that expected discounted expenditure on consumption cannot exceed the expected present value of the life-time income.

4.4. Assuming that the consumer desires the highest possible consumption level, one can write (3) as an equality.

$$
\int_{0}^{\infty} e^{-\delta s}\{y(s)-c(s)\} \pi(s) d s=0
$$

Theoretically a consumer should be able to carry out any consumption plan which satisfies this condition. Generally he can make this possible by an arrangement with an insurance company or a pension fund. In this case there will however be an additional condition imposed. will be

Under the insurance arrangement, the consumer's expected net savings at time $t$

$$
V(t)=e^{\delta t} \int_{0}^{t} e^{-\delta s}\{y(s)-c(s)\} \pi(s) d s
$$

In private insurance it is usually required that

$$
V(t) \geqslant 0 \quad \text { for all } t
$$

The implication of the condition is the familiar one, that the premium reserve held by the company must never become negative.

It is evident that saving through an insurance arrangement subject to conditions (3') and (4) is superior to conventional saving subject to condition (1). Under the latter arrangement the consumer can be expected to leave some positive assets at his death, and from his point of view these must be considered as wasted. With life insurance no such waste will occur. 
4.5. To illustrate the superiority of insurance, define the function $\mu(t)$ by the equation

$$
\mu(t)=\exp \left\{-\int_{0}^{t} \mu(s) d s\right\}
$$

or

$$
\pi^{\prime}(t)=-\pi(t) \mu(t)
$$

Condition (4) then takes the form

$$
\int_{0}^{t}\{y(s)-c(s)\} \exp \left\{-\int_{0}^{s}(\delta+\mu(x)) d x\right\} d s \geqslant 0 .
$$

It is seen that $\mu(t)$, the force of mortality is added to the force of interest $\delta$, so that insurance in fact means that saving takes place at a higher rate of interest. This will clearly be to the advantage of the consumer, since the amount saved at no time will be negative.

4.6. Leaving annuities, consider now a generalized whole life insurance contract under which an amount $b(t)$ is payable if death occurs at time $t$. If premium payments can be represented by a continuous function $p(t)$, the principle of equivalence gives

$$
\int_{0}^{\infty} e^{-\delta t}\left\{p(t) \pi(t)+b(t) \pi^{\prime}(t)\right\} d t=0
$$

Every pair of function $p(t)$ and $b(t)$ which satisfies (5) does not give a feasible insurance contract. One must in addition require that the functions satisfy a condition similar to (4), to the effect that the premium reserve, i.e. the net saving under the insurance contract must never be negative.

4.7. Life insurance of the type described is often bought by - or sold to - a person who wants to provide for his dependents in the case of his death. It is however doubtful if life insurance is a good solution to his problem. An indication of this may be the lack of any authoritative, or generally accepted statements as to how much life insurance a supporter of a family ought to carry.

One rule, which at least has been strongly advocated, is that life insurance should provide a death payment equal to the present value of the insured's future earnings. In the notation used earlier this would mean that the sum insured should be :

$$
b(t)=e^{\delta t} \int_{t}^{\infty} e^{-\delta s y}(s) d s
$$

Even superficial observations indicate that very few such policies with decreasing face value are issued. 
Theoretically an arrangement of this kind can be made by buying a whole life policy, and surrender it gradually as the value of future income decreases with time. There is however little evidence that life insurance actually is used in this way. The rule, usually associated with the name of Solomon Huebner [1964], seems to be based on ideas of doubtful relevance, borrowed from property insurance. The present value of the future income a person can get from his own work is considered as an asset, or a "human capital" belonging to the family. This should be insured as any other asset, so that a death leaves the family's net worth unchanged. In the present context the rule may be a useful illustration of how difficult it is to make correct statements about insurance in general.

4.8. In general life insurance with a large lump sum payment at death seems to be an inefficient way to provide for surviving dependents. Usually these dependents will be faced with the problem of investing the lump sum to that it will supply an adequate income for the rest of their lives.

It is therefore natural to assume that policies of this kind are bought to serve other purposes. One such purpose may be to provide a collateral for loans, and thus relax the strict condition (1), which often will be imposed on a consumer. The main reason for imposing condition (1) may be that the creditor fears that the consumer can die without leaving assets sufficient to cover his debts. The creditor's mind may however be put to rest if the consumer supplies a life policy as collateral for the loan.

4.9. To study this use of life insurance, consider a whole life policy for an amount $b$. From (5) one finds that the single net premium for this insurance contract is :

$$
p=-b \int_{0}^{\infty} e^{-\delta t_{\pi}(t) d t}=b\left\{1-\delta \int_{0}^{\infty} e^{\left.-\delta t_{\pi}(t) d t\right\}}\right.
$$

A fully paid insurance policy of this kind is usually an acceptable collateral for a loan, and should thus release the consumer from the severe restrictions imposed by condition (1). For an arbitrary consumption plan the accumulated debt at time $t$ is

$$
S(t)=e^{\delta t} \int_{0}^{t} e^{-\delta s}\{c(s)-y(s)\} d s
$$

The plan will be feasible if the creditors accept the life insurance contract as collateral for the loan. Assuming that the consumer borrows money also to pay for the premium, one is led to the condition

$$
b \geqslant S(t)+p
$$

for all $t$. The condition can be written in the form :

$$
b \delta \int_{0}^{\infty} e^{-\delta t} \pi(t) d t \geqslant e^{\delta t} \int_{0}^{t} e^{-\delta s}\{c(s)-y(s)\} d s
$$


This is clearly a condition far weaker than (1). In fact for any finite consumption plan, and for any finite $t$, one can find a sum insured $b$, so that (6) is satisfied. This is possible even when the consumer has no income, so this simple insurance arrangement should allow a person to carry out a consumption plan virtually independent of his income - if any.

4.10. It is obvious that insurance arrangements of this kind can generate strong inflationary pressure. If most people want to - and can - spend more than their current income, it is inevitable that prices will go up.

The arrangement is not as far-fetched as it may seem, and this can be illustrated by a numerical example. With the actuarial tables in general use and with 4 per cent interest, the net single premium for a man at age 25 will be about 0.2 per unit of sum insured. Taking $c(t)=1$ and $y(t)=0$ the accumulated debt after 20 years will, with 4 per cent interest, be about 30 , and this gives the condition

$$
b \geqslant 30+0.2 b
$$

or

$$
b \geqslant 37.5 \text {. }
$$

The situation will not be substantially different in the real world, although a loading will be added to the net premium. It is not usual that a young man with only vague prospects of future income, buys a whole life policy with a face value of about 40 times his desired annual consumption, but most companies will be delighted to sell it to him. They may inquire about his health, but not into his financial circumstances, as long as he is ready to pay the single premium on the spot.

Evidently a day of reckoning will come to this young man, when his debt exceeds the amount covered by his life insurance. At that time the only ways out seem to be death or bankruptcy, and the choice should be easy in a society where bankruptcy is not considered a fate worse than death.

4.11. The examples above are not representative of the general use or abuse of life insurance. It may therefore be appropriate to stress once more that life insurance in essence is an instrument for transfering income from one period and make it available for consumption in another period, and possibly in different circumstances. As shown above, the conditions $\left(3^{\prime}\right)$ and (4) will determine a set of feasible consumption plans $c(t)$ for a given income stream $y(t)$. If one makes assumptions about the consumer's preferences, it may be possible to determine the consumption plan which is optimal, and which the consumer will - or should - choose. maximize

The most popular assumption about preferences is that the consumer seeks to

$$
\int_{0}^{\infty} e^{-\gamma t} \pi(t) u(c(t)) d t
$$


subject to conditions ( $\left.3^{\prime}\right)$ and (4). In (7) $\gamma$ represents the consumer's "impatience", and $u(\bullet)$ his "instantaneous utility function". This model can be traced back to Böhm-Bawerk [1889] and was developed by Fisher [1930]. More recently it has been generalized by Yaari [1965] and Hakansson [1969].

If the income is earned early in life, conditions ( $\left.3^{\prime}\right)$ and (4) may not be binding. The problem can then be solved by classical calculus of variation, and the solution is given by the differential equation

$$
c^{\prime}(t)=(\gamma-\delta) \frac{u^{\prime}(c(t))}{u^{\prime \prime}(c(t))}
$$

If the conditions are binding, the solution will give $c(t)=y(t)$ in some intervals.

Formula (8) will give $c(t)=$ constant only if $\gamma=\delta$, i.e. if the impatience is equal to the rate of interest. In all other cases the solution will give a consumption plan which is strictly increasing or decreasing.

\section{Life insurance - Practice}

5.1. Life insurance has its share of conflicts between theory and practice. The most striking example is probably the theory that "human capital" should be insured in the same way as any physical asset. There is little evidence that families do their " estate planning" as they should according to this theory, and it is not unreasonable to assume that there is something wrong with the theory.

Less arbitrary theories than the human capital model also lead to life insurance with decreasing sums as the optimal solution. Few such policies seem to be issued, and there may be some reason to assume that the insurance buyer behaves irrationally. It is however not easy to test any hypothesis of this kind against observations, since during decades of inflation it has turned out ex post that most life insurance policies have been sold with decreasing face value.

5.2. It was observed earlier that life insurance with a large lump sum payment at death may not be the most efficient way to provide for surviving dependents. Usually it will be cheaper to buy annuities which run only if, and as long as, the dependents are alive. On this background it is really surprising that life insurance for large amounts should be widely sold. It may be that many people make the wrong decision when they buy insurance. It is however also possible that some essential element has been assumed away in the theoretical models. When a person with a large life insurance policy dies, his heirs will presumably have to invest the amount in order to obtain income over the years to come. In some cases this may be a difficult problem, involving considerable transaction costs, but in other cases it will give the heirs a freedom of choice which will not be associated with the inheritance of an annuity determined in advance.

Ordinary life insurance is obviously an efficient way of providing the money necessary to cover the cost of the adjustments following the death of a family member, 
but the amounts required for such purposes should be relatively modest, and it seems that greater emphasis should be placed on the sale of annuities.

5.3. Practically all pension plans are designed to give a fixed-level pension, i.e. $c(t)=$ constant after retirement. If preferences can be represented by (7), it follows from (8) that this can be optimal only in exceptional cases.

Statistical studies of consumption and saving often show decreasing or increasing consumption over long periods, i.e. results which are piece-wise consistent with (8). It is however not clear if this - which actually was observed - also was intended when the consumer made his plans. A pension plan represents a pure and binding statement of intentions, and should reflect preferences far more accurately than any economic observations. Such plans are usually the result of careful considerations and negotiations, and it is difficult to accept that the outcome should not be considered as optimal, at least at the time when the plan was adopted. The constant level pension plan may possibly be explained as a compromise between people with impatience of different strength. It seems however a more natural explanation to assume that formula (7) is too simple to represent all shades of preferences. The question has been discussed by some authors, e.g. by Borch [1978].

Consider now a pension plan which provides for a consumption $c(t)=c$ after retirement, i.e. when $y(t)=0$. If the plan is paid for by a premium $r y(t)$, proportional to the income, $r$ will be determined by (3') and (4). Consumption before retirement will then be $(1-r) y(t)$. This may not be optimal, and the consumer can use conventional saving to make his own pre-retirement consumption plan. Life insurance companies might find new markets if they could help the consumer with the problems he has at this stage.

5.4. In the market life insurance competes with other forms of saving. A good salesman must have not only a thorough knowledge of life insurance, but must also know its advantages and disadvantages when compared to mutual funds and other forms of saving.

Most people could save more than they do, and it is possible that they "should" save more. This explains the high pressure salesmanship alleged to be common in life insurance. The salesman must first try to persuade the client that he ought to save more, and only when the client is convinced on this point, can the salesman offer his technical advice and help the client to find the insurance arrangement which is the best possible form of saving.

The fact that people could save more than they do, means that there is no obvious limit to the market for life insurance. More life insurance could be sold if people could be convinced that it is to their advantage to save more, and that life insurance compares favourably with competing forms of saving.

5.5. The example of how life insurance can be used as collateral for consumer's credit indicates that there may be some dilemmas in the marketing of life insurance. In period of strong inflation the real rate of return on savings may become negative, 
and this is not likely to encourage saving. It is therefore natural that insurance companies often appear as strong advocates for any policy measures designed to reduce the rate of inflation.

On the other hand, in their marketing, insurance companies will often stress that some forms of life insurance represent liquid assets. A life policy can be surrended at any time, in part or as a whole, and it can serve as collateral of a loan, in other words it has all the advantages of a savings account in a bank. If the life policy is used in this way to the fullest possible extent, it may make high consumption too easy, and contribute to increased inflationary pressure in the economy.

5.6. We have found that saving through life annuities is superior to conventional risk-free saving. Usually one can expect to earn a higher return if the savings are invested in equities or other assets which involve some risk. In times of inflation this form of investment may appear as an attractive alternative to both conventional saving and to life insurance, and such considerations have led to the development of the equity-linked insurance contract.

The principles behind this kind of insurance contract are very simple. Essentially the insured can decide how his savings shall be allocated between risky and risk-free investments. If the insurance companies can offer flexible contracts, with a wide range of options, new markets may become open to life insurance.

5.7. Life insurance companies are in a sense the custodians of the savings of widows and orphans, and it is generally agreed in most countries that they must operate under strict supervision by the government. The principal objective of the supervision is to make sure that the companies remain solvent so that they are able to meet their obligations. The bankruptcy of a life insurance company can be a tragedy, leading to the loss of a lifetime's savings. In non-life insurance a bankruptcy will usually be less dramatic in its consequences, and can almost be seen as a normal part of business in a risky world.

Another objective of governmental control is to see that the insured gets a fair deal. This does not necessarily mean regulations of premiums to keep them low, or at a "reasonable" level. The premiums must be high enough to ensure solvency, and this usually implies that they also ensure substantial profits to the company. Often government regulations will require that the profits in some form is returned to the policy-holders.

\section{Business insurance - Theory}

6.1. Business insurance, or commercial insurance, can most naturally be seen as form of risk sharing among people engaged in risky business. It is important to realize that insurance is just one of many possible forms of risk sharing. This has been clear right from the beginning of modern insurance. The merchant of Venice might have felt uneasy about putting all his money into one single ship. His alternative, in the absence of insurance, might be to get outside capital through a bottomry loan, or to make arrangements so that he would own, say a 10 per cent interest in 10 ships. 
The theory of risk sharing is relatively new, apparently because older theory lacked the tools necessary to analyse this type of problems. The break-through came with the theory of expected utility, which was developed by von Neumann and Morgenstern [1947] as a by-product of their game theory. One of the first important results in this field is due to Arrow [1953], who showed that a free market for shares in risky ventures would lead to a Pareto optimal distribution of the risks inherent in economic activity. In a way this may be taken to mean that there should be no need for insurance of business risks. Intuitively this may seem an attractive and natural conclusion. If a man owns only a tiny fraction of a risky enterprise, say an off-shore oil rig, he may not insist on full insurance cover for the property. Such entreprises can be incorporated as a company with limited liability, which may or may not be able to borrow capital. The lender may not insist on insurance, if he feels sufficiently compensated by high interests.

6.2. The basic model in the theory of risk sharing consists of three elements :

(i) A set of $n$ persons, each exposed to a risk represented by the stochastic variables $x_{1}, \ldots, x_{n}$.

(ii) The joint probability distribution of the $n$ stochastic variables $F\left(x_{1}, \ldots, x_{n}\right)$.

(iii) The risk aversion of person $i$, represented by the utility function $u_{i}(\bullet), i=1,2, \ldots, n$, with $u_{i}^{\prime}>0$ and $u_{i}^{\prime \prime}<0$.

It is easy to see that the real problem of this set of persons is to agree on some rule as to how the total risk $x=x_{1}+\ldots+x_{n}$ shall be shared. A general arrangement of this kind will specify that if the total loss is $x$, person $i$ shall pay an amount $y_{i}(x)$. Hence an arrangement is represented by $n$ functions of $x$. The only essential restrictions on these $n$ functions is that they must add up to the total loss, i.e. we must have

$$
y_{1}(x)+y_{2}(x)+\ldots+y_{n}(x)=x
$$

An arrangement is called "Pareto optimal" if there exists no other arrangement which is considered at least as good by all persons, and which is strictly preferred by some person. It has been proved by many authors (see Borch [1979] for references) that the set of all Pareto optimal arrangements consists of the functions which satisfy (9) and equation (10) below

$$
u_{i}^{\prime}\left(y_{i}(x)\right)=\mathrm{k}_{i} u_{1}^{\prime}\left(y_{1}(x)\right)
$$

where $k_{1}=1$, and $k_{2}, k_{3}, \ldots, k_{n}$ are arbitrary positive constants.

6.3. It is natural to assume that a group of rational persons in some way will be able to reach a risk-sharing arrangement which is Pareto optimal. If the group is small, the members could conceivably meet, say at Lloyd's coffee house, and negotiate an arrangement of this kind. In a large group the negotiations have to take place within an institutional framework, and they will have to be conducted according to 
rules generally observed and agreed upon. The interesting theoretical problem is then to study how far today's insurance institutions can lead to an optimal risk-sharing arrangement. It is worth noting that $y_{i}(0)$ can be interpreted as the insurance premium which person $i$ pays or receives under the arrangement.

The constants in (10), $k_{2}, \ldots, k_{n}$ can be chosen arbitrarily, so that there will in general exist an infinity of Pareto optimal arrangements. In order to determine a unique arrangement, one will need some additional assumptions about the behaviour of the parties involved, i.e. about how they negotiate their way to an optimal arrangement. In many insurance situations a sufficient additional assumption may be an agreement that some particular method should be used to compute the premiums. For instance if by convention insurance premiums are computed by proportional loading of net premiums, the expression

$$
P(y)=(1+\lambda) \int_{0}^{\infty} y(x) d F(x)
$$

will give the premium one has to pay to receive a compensation $y(x)$ if total loss amounts to $x$. The special case of this formula, with $\lambda=0$, has been studied in some detail by Jewell and Bühlmann [1979], who argue that it in many cases will give a reasonable Pareto optimal arrangement, which should be acceptable to all parties.

6.4. In general an insurance premium will consist of three elements, and it is convenient to write

$$
P=E\{x\}+A+R .
$$

Here $E\{x\}=$ the " net premium", i.e. expected claim payments,

$\boldsymbol{A}=$ the administrative expenses,

$R=$ the reward for risk bearing.

The typical contract in business insurance can lead to very large claims, and one must expect that the insurer will demand a substantial reward for accepting such risks.

The administrative expenses are not negligible, but they can be ignored in a first approach to the problem. The premium which person $i$ will have to pay to have is initial risk covered by insurance will then be

$$
P_{i}=E\left\{x_{i}\right\}+R_{i}
$$

A natural extension of (11) will be to write

$$
P\left(F_{i}\right)=(1+\lambda) E\left\{x_{i}\right\}+\beta \operatorname{var}\left\{x_{i}\right\}
$$

This formula which is widely used, implies that the premium depends only on the probability distribution of $x_{i}$, say $F_{i}\left(x_{i}\right)$, a marginal distribution of $F\left(x_{1}, \ldots, x_{n}\right)$ introduced earlier. This is clearly an arbitrary and unsatisfactory restriction. 
6.5. Formula (13) has the desirable property of being additive when applied to independent stochastic variables. If $x_{i}$ and $x_{j}$ are independent, the denstity of the sum $x_{i}+x_{j}$ will be the convolution $F_{i}{ }^{*} F_{j}$, and one has

$$
P\left(F_{i}^{*} F_{j}\right)=P\left(F_{i}\right)+P\left(F_{j}\right)=(1+\lambda)\left(E\left\{x_{i}\right\}+E\left\{x_{j}\right\}\right)+\beta\left(\operatorname{var}\left\{x_{i}\right\}+\operatorname{var}\left\{x_{j}\right\}\right) .
$$

Thus the total premium will be the same whether two independent risks are insured separately, or under one single contract. This is only what one would expect in a rational group, when transaction costs are ignored.

If $x_{i}$ and $x_{j}$ are not independent, let their joint distribution be $F\left(x_{i} x_{j}\right)$, with marginal distribution $F_{i}$ and $F_{j}$. Let further $G(x)$ be the distribution of $x=x_{i}+x_{j}$. Application of formula (13) to the distribution $G$, gives the premium

$$
P(G)=(1+\lambda) E\left\{x_{i}+x_{j}\right\}+\beta \operatorname{var}\left\{x_{i}+x_{j}\right\}
$$

Here

$$
\begin{aligned}
& \operatorname{var} x=\operatorname{var}\left(x_{i}+x_{j}\right)=\operatorname{var} x_{i}+2 \operatorname{cov} x_{i} x_{j}+\operatorname{var} x_{j} \\
& \operatorname{cov}\left\{x_{i}\left(x_{i}+x_{j}\right)\right\}+\operatorname{cov}\left\{x_{j}\left(x_{i}+x j\right)\right\} \\
& =\operatorname{cov}\left\{x_{i} x\right\}+\operatorname{cov}\left\{x_{j} x\right\} .
\end{aligned}
$$

This gives the additive formula

$$
P(G)=(1+\lambda) E\left\{x_{i}\right\}+\beta \operatorname{cov}\left\{x_{i} x\right\}+(1+\lambda) E\left\{x_{j}\right\}+\beta \operatorname{cov}\left\{x_{j} x\right\}
$$

Returning to the particular risk of person $i$, one arrives at the premium

$$
P\left(F_{i}\right)=(1+\lambda) E\left\{x_{i}\right\}+\beta \operatorname{cov}\left\{x_{i} x\right\} .
$$

This means that the premium depends not only on the marginal distribution $F_{i}\left(x_{i}\right)$, but also on how $x_{i}$ is correlated with other risks in the group. Clearly (14) reduces to (13) when $x_{i}$ and $x_{j}$ are stochastically independent.

6.6. Formula (14) is virtually identical to the main result of the so-called Capital Asset Price Model (CAPM) due to Mossin [1966] and others, which has become extremely popular in the theory of finance during the last 15 years. With our formalistic derivation the formula appears as just a reasonable way of loading premiums. It is however easy to derive the formula as a special case of Arrow's model from 1953, and show that it gives the equilibrium price of a risky asset in a competitive market. By simple reversion of signs, the model can be interpreted as the premium one has to pay to get rid of a liability in a competitive insurance market.

One of the main objections to CAPM is that only the two first moments of the probability distributions are taken into consideration. This means that the model will be an approximation, except if : 
(i) all preferences can be represented by quadratic utility functions, or

(ii) if all stochastic variables are normally distributed.

It is however fairly easy to generalize the model. The cumulants of a distribution, $x_{1}, x_{2}, x_{3}, \ldots$ are defined by the expansion

$$
\sum_{n=1}^{\infty} \frac{(i t)^{n}}{n !} x_{n}=\log \int_{-\infty}^{+\infty} e^{i t x} d F(x)
$$

The first two cumulants are respectively the mean and the variance. For the normal distribution cumulants of higher order are zero. For other distributions the cumulants have the same additivity properties as the mean and variance. The cumulants of higher order will however lead to cumbersome expressions, and the generalization does not seem to have been tried in practice.

6.7. The functions defined by (9) and (10) will in general have a complicated form. For instance in the case of $n=2$,

$$
u_{1}(x)=x^{1 / 2} \quad \text { and } \quad u_{2}(x)=x^{3 / 4}
$$

one finds

$$
\begin{aligned}
& y_{1}(x)=\left(h^{2}+4 h x\right)^{1 / 2}-h \\
& y_{2}(x)=x+h-\left(h^{2}+4 h x\right)^{1 / 2}
\end{aligned}
$$

The market equilibrium condition will be

$$
(1+\lambda) E\left\{x_{i}\right\}+\beta \operatorname{cov}\left\{x_{i} x\right\}=(1+\lambda) E\left\{y_{i}(x)\right\}+\beta \operatorname{cov}\left\{y_{i}(x) x\right\}
$$

This expression, and any further analysis will be fairly simple if the functions $y_{1}(x), \ldots, y_{n}(x)$ are linear, i.e. $y_{i}(x)=a_{i} x+b_{i}$. It can be proved that this will happen if and only if the utility functions of all persons belong to one of the following three classes :

(i) $u_{i}(x)=\left(x-c_{i}\right)^{\alpha}$

(ii) $u_{i}(x)=\log \left(x-c_{i}\right)$

(iii) $u_{i}(x)=1-e^{-\alpha_{i} x}$.

Positive linear transformations of these functions will of course lead to the same results, since $u(x)$ and $w(x)=A u(x)+B$, with $A>0$, represent the same preference ordering. 
Any of these classes seems too narrow to give room for the individual attitudes to risk which we would expect in to find in the real world.

\section{Business insurance - Practice}

7.1. Intellectually it may be very satisfactory to extend the standard theory of competitive markets to insurance. It is however debatable whether the resulting models are very relevant in the real world. Under free competition the invisible hand of Adam Smith should steer the market to a Pareto optimal situation. In the real world some very visible brokers seem to be needed to reach this result. The activities of these brokers presumably lead the market closer to an optimum, but it is doubtful if they lead to a completely Pareto optimal situation. It is even more doubtful if the activity will approach the particular Pareto optimum which corresponds to the competitive equilibrium, i.e. the risk sharing arrangement defined by (15).

7.2. When we confront the theory with observations from the real world, it is disturbing that many of the risk-sharing arrangements which we see must be far from optimal, under assumptions about preferences which appear reasonable. It is a real challenge to identify the conventions and institutional aspects which bar the way to a Pareto optimal arrangement, and possibly to have them eliminated, but this may be a formidable task. At the present stage it may be appropriate to recall that the world is not entirely capitalistic. Shareholders and creditors may diversify their portfolios so that they can be able to shoulder the loss they incur if a firm goes bankrupt because its fire insurance turned out to be inadequate. The employees of the firm, who lose their jobs are in a different position. They may be against the firm's extensive self-insurance, also when the risks are acceptable to owners and creditors. To society as a whole, the loss caused by fire is of course the same, whether it is covered by insurance or not. The role of insurance, or alternative arrangements are to divide the loss in an acceptable way. It is evident that some essential elements are assumed away when one tries to analyse the situation in the framework of a theory for capital markets.

7.3. In the market the insurance offered to businessmen competes with other arrangements for sharing or reducing risks. The risk manager of a corporation may often be the key person to be convinced that insurance is the best solution to his problems. A firm of any size will usually self-insure to some extent, and it may be worth while to incur some expenses to find the best form of self-insurance, and often creditors and employees may want to influence the decision.

The risk manager will have to consider alternative arrangements, such as leasing, which may be more advantageous than buying and insuring plant and equipment. If the risk manager chooses to lease, the potential buyer of insurance will be the leasingcompany, which may, or may not decide to self-insure.

7.4. Large corporations will often be in a position where they deal with insurance companies on almost equal terms. Through negociations they reach agreement on some risk-sharing arrangement which is acceptable to both parties. During the negociations they may both have to consider the wishes of third parties, such as reinsurers 
and creditors, and also the deals they may be able to make with competing insurance companies or other financial institutions. Usually one says that these negociations take place in a market, but the whole process is essentially different from the concept of competitive markets in conventional economic theory. The situation obviously invites analysis in terms of game theory.

7.5. If some businessmen and their corporations act as a group, they will be in an even stronger position in their dealings with insurance companies. A group of this kind can make its own risk-sharing arrangements - possibly registered as an insurance company. The classical example is the $\mathbf{P} \&$ I clubs, which originally were organized to cover risks which marine insurers could not, or would not accept. There are other examples, and one must expect that such arrangements will at least be discussed in new fields, for instance to cover product liability.

During the last decade many large corporations have formed their captive insurance companies. These companies exchange risks among themselves, and they may negotiate their way to a risk-sharing arrangement which is approximately optimal without any help from established insurance institutions. Here is a real challenge to today's insurers. They can exist and prosper only by proving that they can do the job better than their prospective clients can on a do-it-yourself basis.

7.6. There can be no firm boundaries to the market for business insurance. It is always conceivable that enterprising insurers may devise insurance contracts covering risks which traditionally were shared by other arrangements. Theoretically it may be possible to handle virtually all risk-sharing in the economy through insurance companies. It is however doubtful if a development in this direction would be desirable. The owner of a resort hotel can insure against losses caused by bad weather, but not against losses due to sloppy management and poor service. Insurance should not remove all incentives to take care and do good work.

In some cases it may be possible to avoid some risk by organizing a risky venture as a company with limited liability. If this company should incur heavy liabilities, it may go bankrupt, without any substantial loss to the owners. In such cases the government may introduce compulsory insurance, to ensure that claims against the bankrupt company are paid. With stricter liability legislation, for instance on product liability, new markets may be created for insurance, out of the government's concern for third parties. These may be the ordinary man or the ordinary household, so this element is most naturally considered in the following, in connection with the third class of insurance. It may however be worth noting that the market which is created in this way may reduce the market for personal accident insurance.

7.7. There is no strong and obvious need for any special governmental supervision or control of business insurance. The transactions are made between businessmen, who prefer to make any contract which they find mutually advantageous. The only requirement should be that society maintains the law and order essential to any kind of business. It is desirable that the government should settle disputes and punish fraud, but there should be no need for legislation to protect, say a shipping company from being exploited by its insurer. In fact many marine underwriters may argue that they are the ones that need protection. 
Reinsurance can be considered as the extreme member of the class of business insurance, since it is an arrangement concluded between professional insurers. There should be no need for governmental protection of any party to such arrangements, and in most countries the legislation will exempt reinsurance, at least from the detailed regulation of direct insurance.

\section{Household Insurance - Theory}

8.1. By household insurance it is natural to understand the insurance bought by the ordinary consumer, or by the "little man". He is rarely in the position to bargain with the insurance company, but he is usually offered a fairly wide choice of different insurance contracts.

These insurance contracts are clearly sold in a mass market, and there is usually a strong competition among the sellers. This should indicate that the standard theory of competitive markets could be used to analyse this class of insurance. There are however a number of difficulties. One of these is that there is no obvious natural unit of insurance cover. If a client chooses a higher deductible, he clearly buys less insurance, but it is not easy to state how much less, and it is not clear how one shall formulate the familiar demand relation between price and quantity bought. This dependence between quantity bought (or sold) and price is the starting point of most conventional economic analysis, and it seems that a different approach is required.

8.2. The premium is relatively low for most household insurance policies. This means that transaction costs will be relatively high, i.e. the companies' expenses on sales and administration constitute an important part of the premiums charged to the public.

Returning to the equation

$$
P=E\{x\}+A+R
$$

it is natural to assume that the term $A$ is substantial. On the other hand $R$ - the charge the insurer makes for his risk-bearing services - may be insignificant. This means that one can assume that the insurance company is approximately risk neutral. It has been proved by many authors, most generally by Arrow [1974], that in this case the solution to equations (9) and (10) is of the form

$$
\begin{array}{lll}
y(x)=0 & \text { for } & x<D \\
y(x)=x-D & \text { for } & x \geqslant D .
\end{array}
$$

Here $y(x)$ stands for the compensation the consumer will receive if his loss is $x$. The interpretation is that he will carry losses less than the deductible himself, and have all excesses completely covered by the insurance policy.

8.3. Competition has forced companies to make every effort to reduce administrative expenses and this has led to a tendency towards standard contracts and 
standard premiums. This again means that companies knowingly underwrite good and bad risks at the same premium, simply because it would be too expensive to examine all risks and classify them correctly. This leads to a new and fascinating set of problems, which first were examined by Rothschild and Stiglitz [1976].

The simplest model studied by Rothschild and Stiglitz can be described as follows :

A person with initial wealth $W$ is exposed to a risk which can lead to a loss $x$ with propability $\pi$.

The person can pay a premium $c P, c \leqslant 1$ to an insurance company, which in return undertakes to pay a compensation $c x$ if the loss occurs.

If the person's preferences can be represented by the utility function $u(\bullet)$, his problem is to determine the value of $c$ which maximizes expected utility :

$$
U(c)=(1-\pi) u(W-c P)+\pi u(W-c P-x+c x) .
$$

The first order condition for a maximum is

$$
(1-\pi) P u^{\prime}(W-c P)=\pi(x-P) u^{\prime}(W-c P-x+c x)
$$

It is easy to see that $c=1$ is a solution if $P=\pi x$. For $P>\pi x$ one will have $c<1$ if $u^{\prime \prime}<0$, i.e. a risk averse person will not buy full cover.

This result may be surprising. The premium must cover the company's administrative expenses, so in general one will have $P>\pi x$, but casual observation indicates that most people take full cover, if they buy insurance at all.

8.4. If administrative expenses can be ignored, and there is perfect competition in the insurance market, it can be argued that one must have $P=\pi x$, which implies that the company's expected profits is zero.

Assume now that there are two types of risks in the market, good and bad, with claim probabilities respectively $\pi_{G}$ and $\pi_{B}$, and $\pi_{G}<\pi_{B}$. Assume further for the sake of simplicity that the number of risks in each group are equal, and take $x=1$.

If the company can distinguish the two types of risk, there is no problem. Each group will be charged the premium $P_{G}=\pi_{G}$ and $P_{B}=\pi_{B}$ respectively, and they will both buy full insurance cover.

The problems occur when the insurance company is unable to, or not allowed to, distinguish between the two groups and quote different premiums. These problems are essential in insurance, and are particularly relevant in household insurance. The premiums are small and it will be prohibitively expensive to make them fair for each group of customers - i.e. to examine each risk and determine the fair premium which it should be charged.

8.5. In household insurance it is necessary to sacrifice some fairness in order to reduce administrative expenses. This means that the same premium will be charged 
to each member of a group of heterogenous risks. In the example above this implies that the same premium $P$ will be charged for both good and bad risks. It is natural to assume $\pi_{G} \leqslant P \leqslant \pi_{B}$.

The customers representing the bad risks will in this case buy full cover. Those representing the good risk will take a cover $c<1$, determined by the equation

$$
\left(1-\pi_{G}\right) P u^{\prime}(W-c P)=\pi_{G}(1-P) u^{\prime}(W-c P-1+c) .
$$

If there is perfect competition in the market, the insurance company's profits will be zero. This gives the equation

$$
c\left(P-\pi_{G}\right)+P-\pi_{B}=0
$$

or

$$
(1+c) P=c \pi_{G}+\pi_{B}
$$

8.6. If the equations (16) and (17) have a solution in $c$ and $P$, this will constitute an equilibrium. It is however not obvious that the equations have a meaningful and unique solution.

If the equations give a solution with $c<0$, the only meaningful equilibrium is obviously $c=0$ and $P=\pi_{B}$. In this case only the people representing bad risks will buy insurance, and they will take full cover. This arrangement can hardly be said to be optimal in any usual sense of the word.

Thus in the model presented by Rothschild and Stiglitz it is doubtful if a competitive equilibrium exists, and if it exists it may not be Pareto optimal. This shows that some of the central results in conventional economic theory do not seem to hold in the market for household insurance. The reason is clearly that one party to the transactions has imperfect informations about the risks insured.

8.7. The insurance company may not know ex ante if a customer represents a good or a bad risk. In the model the company will however know ex post when the customer has made his decision. If the customer chooses full cover, i.e. $c=1$, he must represent a bad risk, and should have been charged a premium $P=\pi_{B}$. If on the other hand the choice is $c<1$, the customer represents a good risk, and could have been offered full cover at a lower premium.

The new idea emerging from these observations is that the customer, when making his decision must send a "signal", or convey some information to the insurance company. The problem of the company - or more generally of the other party to the transaction - is then to interpret the signal correctly, and make appropriate use of the information.

8.8. One suggestion made by Rothschild and Stiglitz, and developed further by Wilson [1977] is that the insurance company could offer two standard contracts defined 
by the pairs $\left(c_{1}, P_{1}\right)$ and $\left(c_{2}, P_{2}\right)$. The former offers a compensation $c_{1}$ against a premium $P_{1}$, and correspondingly for the second. If these pairs are chosen so that customers representing good risk prefer the former contract, and those representing bad risks prefer the latter, one can obtain some fairness. There will however still be difficulties about the existence of a competitive equilibrium, and about the Pareto optimality of the equilibra.

8.9. The fairly recent results outlined above represent an approach to essential problems in economic analysis of household insurance. The results are however obtained for extremely simple examples, and it is not easy to see how they can be generalized to more realistic models.

A more realistic case would be to assume that the loss is represented by a stochastic variable with a density $f(x)$. One can then assume that an insurance contract specifies that a compensation $c x$ is paid if the loss is $x$, and that the premium to be paid is $c P$. The problem of the customer is then to determine the value of $c$ which maximizes

$$
U(c)=\int_{0}^{\infty} u(W-x+c x-c P) f(x) d x
$$

The first order condition for a maximum is

$$
U^{\prime}(c)=\int_{0}^{\infty}(x-P) u^{\prime}(W-x+c x-c P) f(x) d x=0 .
$$

It is easy to see that

$$
U^{\prime}(I)=\int_{0}^{\infty}(x-P) u^{\prime}(W-c P) f(x) d x=(E\{x\}-P) u^{\prime}(W-c P) .
$$

From this it follows that $c=1$ can give a maximum only if $E\{x\}=P$. It is easy to show that if $P>E\{x\}$ the maximum is obtained for some $c<1$, i.e. the customer will not buy full insurance cover if the premium exceeds the expected loss.

8.10. The example above seems to indicate that the results in this section can be generalized fairly easily. This is however deceptive, since the maximizing was carried out under the arbitrary assumption that the compensation should be proportional to the loss, i.e. $y=c x$. In a more general formulation the insurance contract could specify that a compensation $y(x)$ should be paid if the loss amounts to $x$. This leads to the problem

$$
\max _{y(x) \in Y} \int_{0}^{\infty} u\left(W-P_{y}-x+y(x)\right) f(x) d x
$$

where $Y$ is the set of permissible compensation functions. 
If $Y$ consists of all functions such that $0 \leqslant y(x) \leqslant x$, the solution is as mentioned earlier an insurance contract with full cover above a fixed deductible $D$. By maximizing (18) one assumes that $y(x)=c x$, and this must lead to a sub-optimal solution.

The examples above illustrate the limitations of the simple model introduced by Rothschild and Stiglitz. In this model, based on a two-point claim distribution, it is not possible to distinguish between a policy with a deductible, and one with a compensation proportional to the loss. If the loss can take several non-negative values, the two contracts become different, and this leads to new problems, which seem to merit further research.

\section{Household insurance - Practice}

9.1. The most striking conflict between theory and practice in household insurance may be that a consumer should never buy full insurance cover. It would indeed be surprising if a traveller deliberately insured his baggage for say 80 per cent of its value but this is what he would do if he solved his problem by maximizing (18). One explanation may be that there is some element of "impulse buying" in insurance, and that a consumer does not really bother to maximize his expected utility when small amounts of money are involved. Another may be that the problem represented by (18) does not lead to an optimum. If the consumer was offered a choice of different deductibles, he might have been able to reach a more rational decision.

9.2. Insurance is usually the only way in which the ordinary consumer can be relieved of the risks he carries. Hence the market for household insurance is in a sense self-contained. Insurance companies compete among themselves to cover the insurance needs of a large, but finite number of households. The market will evidently expand with general economic growth, but further expansion may be possible only if the public at present is underinsured. One should of course not rule out the possibility that insurance companies through innovations can find ways of insuring risks which households at present must carry themselves. One example is the legal assistance insurance which has become very popular in some countries. The origin of this form of insurance seems to be market studies which revealed that one of the few important risks which is uncovered in a modern society is the risk of becoming involved in a law suit, without any fault of one's own.

9.3. There are elements which indicate that the market for household insurance many shrink in the future. Then tendency to stricter liability legislation may reduce the apparent need for personal accident insurance, and hence transfer some insurance from the household - to the business class. It is debatable if this is a desirable development. A good personal accident policy should secure adequate compensation to the victim, without forcing him to go to court. If liability is involved, the settlement could be arranged out of court, between the insurance companies of the victim and the one responsible for the accident.

9.4. In most countries the government has taken special action to protect the buyer of household insurance - because he is assumed to be the weaker party to 
the insurance contract. With the rise of the consumers' movement there has been increasing pressure for stricter governmental control and supervision of insurance companies and their operations. The organized consumers want low premiums and generous claim settlements, and often seem to have the political strength necessary to obtain legislation assumed to have this effect.

It is obvious that pressure for low premiums can lead to conflicts with solvency requirements. Good insurance cannot be cheap. If the solvency requirements are not relaxed, it may be tempting to seek solutions outside the insurance industry. An automobile manufacturer, or a car dealer with good repair facilities can offer to do any necessary repairs to the cars they sell, against a premium paid in advance. This will probably be cheaper to the buyer than conventional collision insurance, and the question has come up in some countries, i.a. in Scandinavia. The governments have stood firm, and insisted that such guarantees can be given only by companies under the same supervision as insurance companies, and this again has led to the formation of at least one captive company.

\section{Some conclusions}

10.1. Our classification was based on theoretical consideration, but it seems that the division of insurance into three classes is widely applied, although informally so in practice. It may be advantageous to do this more explicitly and use it also in official statistics and legislation.

Insurance companies certainly need specialists on evaluating fire risks, possibly organized in a separate department. When it comes to marketing it is however likely that they will not use the same agents to sell fire insurance to homeowners and to industrial clients.

10.2. In the supervision of private insurance it is generally recognized that life insurance must be considered as a class by itself, and subjected to strict control. It may even be argued that pension plans should be treated differently from life insurance contracts which give the insured the right to surrender his policy for cash at any time. To some extent this is already done, as the two classes of life insurance in many countries are considered differently for taxation purposes.

It may be desirable that the two other classes also should be subjected to two different sets of rules. The households presumably welcome government supervision as a means to secure fair deals from insurance companies. The businessmen on the other hand are likely to consider detailed supervision as undesirable government interference.

10.3. For theoretical reasons it is always desirable to pool as many different and independent risks as possible. It is generally accepted that in some years profits from business insurance is used to cover the company's losses on household insurance, or vice versa. Something will obviously be lost, if the two classes are separated, and written by insurance companies operating under different rules. It is however possible that something may be gained by making the separation official and legal, and leaving the last step in the risk-sharing to reinsurers. 


\section{REFERENCES}

ARROW, K. J. [1953] : "Le rôle des valeurs boursières pour la répartition la meilleure des risques", Colloques Internationaux $d u$ CNRS, Vol. XL, Paris, 41-48. Translated into English with the title: "The role of securities in the optimal allocation of risk-bearing", Review of Economic Studies, 31 (December 1964), 91-96.

ARROW, K. J. [1974]: "Optimal insurance and generalized deductibles", Scandinavian Actuarial Journal (No 1, 1974), 1-42.

BÖHM-BAWERK, E. von [1881]: Rechte und Verhältnisse vom Standpunkte der Volkswirtschaftlichen Güterlehre, Innsbruck.

BÖHM-BAWERK, E. von [1889] : Positive Theorie des Kapitals, Vienna.

BORCH, K. [1978] : "Consumption and saving: Models and reality", Theory and Decision, 9 (September 1978), 241-253.

BORCH, K. [1979]: “Mathematical models for marine insurance”, Scandinavian Actuarial Journal (No 1, 1979), 25-36.

BÜHLMANN, H., and JEWEL, W.S. [1979]: "Optimal risk exchanges", The ASTIN Bulletin, 10 (No 2, 1979), 243-262.

FISHER, I. [1930]: The Theory of Interest, Macmillan, New York.

HAKANSSON, N.H. [1969] : “Optimal investment and consumption strategies under risk, an uncertain lifetime, and insurance ", International Economic Review, 10 (October 1969), 443-466.

HUEBNER, S. S. [1964] : “ Human life values - Role of life insurance ”, in Life and Health Insurance Handbook, 2nd edition, Richard D. Irwin, Homewood (Illinois).

LINDENBAUM, J. [1931] : "Ein Vierteljahrhundert der Bedarfstheorie der Versicherung”, Zeitschrift für Nationalökonomie, 2 (March 1931), 75-99.

MOSSIN, J. [1966] : "Equilibrium in a capital asset market", Econometrica, 34 (October 1966), 768-783.

NEUMANN, J. von, and MORGENSTERN, O. [1947]: Theory of Games and Economic Behavior, 2nd edition, Princeton University Press.

ROTHSCHILD, M., and STIGLITZ, J. [1976]: "Equilibrium in competitive insurance markets: An essay on the economics of imperfect information ", Quarterly Journal of Economics, 90 (November 1976), 629-649.

WILLETT, A. H. [1901] : The Economic Theory of Risk and Insurance, Columbia University Press. Reprinted by Richard D. Irwin, 1951.

WILSON, C. [1977] : "A model of insurance markets with incomplete information ", Journal of Economic Theory, 16 (No 2, 1977), 167-207.

YAARI, M. [1965] : "Uncertain lifetime, life insurance, and the theory of the consumer", Review of Economic Studies, 32 (April 1965), 137-150. 